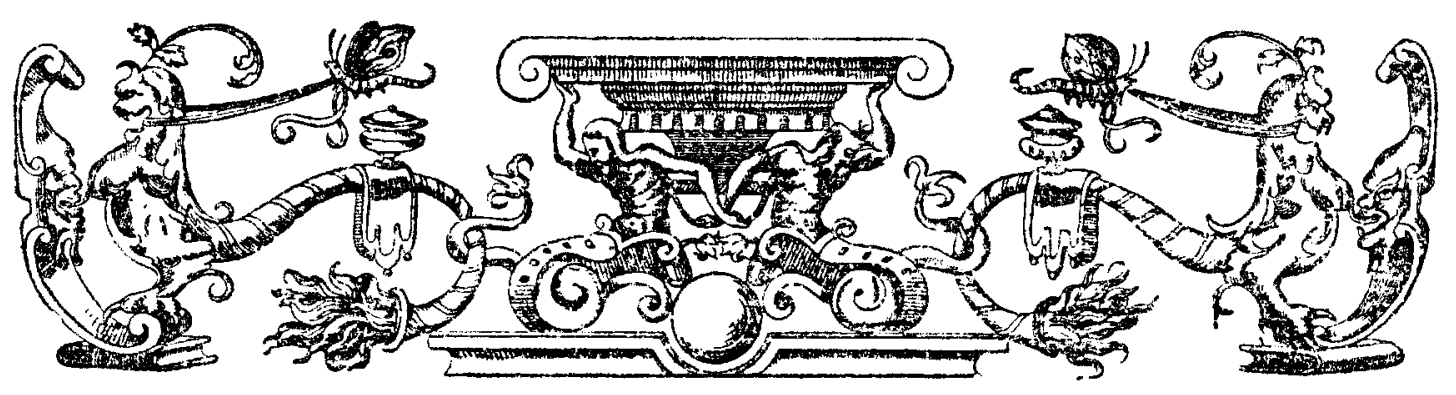

\title{
Dirck Jansz. en Dirck Reyniersz. van der Dou,
}

twee Delftsche ,glasschrijvers", vervaardigers van glas XXV in de St. Janskerk te Gouda,

DOOR

Dr. G. MORRE.

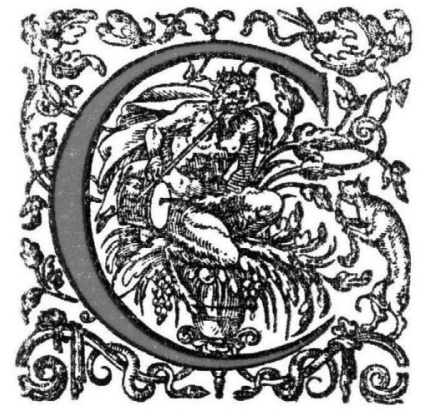

J. DE LANGE VAN WiJNGaERdeN in zijn werkje "De Goudsche Glazen" enz. ('s-Gravenhage, 1819), zegt op blz. $47 / 9$ het volgende:

„In het jaar I603 schonk de stad Delft het een-en-dertigste glasschilderwerk of $25^{\mathrm{e}}$ glas volgens de uitlegging, aan de stad en kerk, naast het voortgaande oostwaards, en achter den predikstoel, verdie $v$ an Delft met der Goude en Rotterdam zoo veel hadden toegebracht....

Dit glastafereel was door denzelfden Leidschen burgemeester SwaneNBURG geteekend, waar van de keurige teekening nog in wezen is, en geschilderd door den Leidschen schilder CORNELIS CLOECK, zooals men voorgeeft, zegt WALvis 1), maar dat de meergemelde WILLEM TOMBERG 2) verhaald had, dat de kleindochter ${ }^{3}$ ) van Dirk Reyniersz. VAN DER Douw van Delft op den 21 Junij 1693 hem verzekerd had, dat het door haren grootvader was geschilderd.

1) W(ALris), J. Beschrijving der stad Gouda. Gouda en Leiden (1713!. 2 din. $4^{0}$.

5) Een Goudsch glasschilder. (Zie Walvis, ble, 327).

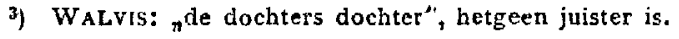


Deltt zoude dan een' glasschilder hebben gehad, op wien zij mede, gelijk Leiden, konde roemen. Dan verhalen van TOMBERG durf ik weinig gelooven."

Deze uitspraak van DE LANGE VAN WIJNGAERDEN gaf mij aanleiding een omvangrijk onderzoek in het Delftsch Archief in te stellen, hetgeen geleid heeft tot een alleszins bevredigend en positief resultaat. De tallooze fiches, gedurende lange jaren door mij in genoemd Archief gemaakt ten behoeve mijner historische, genealogische en heraldische nasporingen, kwamen mij hierbij zeer goed te pas en spaarden mij vele tijdroovende onderzoekingen.

Het is mij mogen gelukken wetenschappelijk vast te stellen, dat het glasraam, 1) door Delft in 1603 aan Gouda geschonken, niet alleen door ćén, maar zelfs door twee Delftsche glasschilders vervaardigd is.

De mededeeling van WiLlem Tomberg blijkt in hoofdzaak waarheid te bevatten en de insinuatie aan zijn adres door DE LANGE VAN WIJNGAERDEN is hier gansch onverdiend.

Het verheugt mij, dat ik op deze wijze niet slechts een steentje kan bijdragen tot betere kennis van een der wereldberoemde Goudsche glazen en het glasschilderen in het algemeen, doch vooral, dat twee nog geheel onbekende glasschilders uit de vergetelheid zijn opgedoken; ten slotte, dat mijnc geboortestad, waar de edele kunst van glasbranden door den heer J. L. Schouten in eere werd hersteld en zulk eene hooge vlucht genomen heeft, ook in vroegere tijden op dit gebied geen vreemdeling was.

In het zoogenaamd "Loopend Memoriaal van Burgemeesteren van Delft" (Archief van Delft, Inventaris Iste afdeeling No. 408) lezen wij in deel $I:{ }^{2}$ )

„Den XVIIen december anno XVIC gheordonneert IsaCK LAMbrechtsZ. VAN DER WEL te betaelen aen DIRCK JANSZ. glaeseschrijver omme bij hem verstreckt te worden tot cope van glas volghende den last hem bij mijnen heeren gegheven de somme van . . . . . . . . . . . . . . . . . I50-0-o

Ten selven daeghe hebben mijnen heeren burghemeesteren allegaeder collegialiter vergaedert wesende den voorsz. DIRCK IANSZ. aenbesteet te maecken des stadts glas inde kercke vander goude, daerinne hij schrijven sal het ontset van leyden - maeckende dat naeden eijssche vant werck, daer vooren hij gheeijsschet heeft seven hondert ende hebben mijnen heeren hem gheboden ses hondert guldens, ende is gheseijt dat men blijvende tusschen beijden van de voirsz. somme hem betaelen sal naer het werck vereijsschen sal, welcke alhier ghestelt is voor - Memorie."

1) Eene flinke photographische afbeelding van dit glasraam vindt men in dit werk van F. Harting, getiteld: "Photographien der geschilderde korkglazen van de St. Janskerk te Gouda" enz. (Gouda), z. j. 4".

2) Deze acte is indertijd ontsnapt aan het scherp ziende oog van wijlen Mr. J. SoutrNDAM, den geleerden Archivaris, iater Secretaris der gemeente Delft. 
(In margine links:) „DIRCK IANSZ. glaseschrijver.

Den XXIIII Januarij anno XVIC ende vier heeft DIRCK REYNIERSZ. glaseschrijver inde molestraet aenghenomen dit glas te volmaecken, ende ter goude inde kercke te stellen, vuijterlijcke voor sint gillis ${ }^{1}$ ) eerstcoemende ende daer vooren mijnen heeren hem toegheseijt hebben driehondert ende vijfftich guldens, ende sullen mijnen heeren boven den hondert ende vijffich guldens die wijlen DIRCK IANSz. ontfanghen heefft ten proffijtte van zijnen boel noch betalen hondert ende vijfftich guldens in voldoeninghe vant werck dat bij hem ghemaect is."

(In margine rechts:) „Den XXIIII Augusti anno XVIC vier betaelt aen DIRCK REYNIERSZ. bij ordonnantie op JAN IANSZ. MOLLJN de somme van driehondert ende vijftich guldens, met noch twaeleff guldens bij hem voor de patroon betaelt. Den laesten aprille anno XVIC ende vijff gegheven aen JAN IAssz. MOLIjN, als Memorie." 2)

Bovenstaande acten hebben verder geene toelichting noodig. Wij leeren er uit welk honorarium ${ }^{3}$ ) de beide glasschilders voor hun werk ontvingen, benevens de kosten van het materiaal.

In den loop van het jaar I603 had DIRCK JANsz. zijn arbeid nagenoeg voltooid. Het jaartal 1603 is dan ook te vinden onderaan op het glasraam (nAnno 1603"), maar door den dood werd hij verhinderd zijn kunstarbeid geheel af te maken en af te leveren. DIRCK JANsz. stierf begin October van genoemd jaar cn zijne begraafacte in het Begraafregister der Nieuwe Kerk te Delft luidt:

6 October I603. "DiRCK JANSZ. glaesmaecker in de nieuwestraet."

In het "Kohier van het haardstedengeld over Delft ao. 1600" (Archief van Delft, Inventaris Iste afd., $n^{\circ} .589$ ) vindt men op fol ${ }^{\circ} .410,14^{\text {de }}$ kwartier, Nieuwstraat:

„DirCK JANSSOON glaesmaecker zeyt te hebben Haertsteeden . . . . . . . . . . . . . . . . . . . . III."

DIRCK JANSz, bezat alzoo 3 haardsteden, hetgeen wijst op eene tamelijk ruime woning en een wellicht niet onaanzienlijk vermogen. Eigenaardig is het, dat het cijfer III eerst IIII is geweest, welk laatste getal in het register is doorgestreept. Het zoude niet onmogelijk zijn, dat DiRCK JANSz. zijn oventje, dat hij als glasbrarder noodig had, niet als haardstede heeft behoeven aan te geven, hoewel wij bij zijn opvolger Dikck Reyniersz. wel een oven als aangegeven ontmoeten.

1) I September.

$\Rightarrow$ Ik achtte het van belang deze interessante posten volledig en woordcijk in den tekst op te nemen. De afkortingen hier en elders zijn door mij opgelost en enkele kleinigheden, zooals $v$ veranderd in $u$ enz. ann gebracht.

3) Vermakelijk is het gemarchander tusschen den Magistraat van Delft en den "glasschrijrer". 
Omtrent DiRck Jansz. heb ik tot heden, jammer genoeg, geene nadere levensbijzonderheden kunnen ontdekken. Ten jare 1600 leefden te Delft niet minder dan drie "glasmakers", allen van denzelfden naam DIRCK JANSz., weshalve en ook om andere redenen niet uit te maken is, welke DIRCK JANSz. het was, die als poorter van Delft, komende uit of geboren te Nijmegen, werd ingeschreven $20 \mathrm{Mei}$ 1587. Iste Poorterboek van Delft (Archief van Delft, Inventaris Iste afd., no 404).

Ao. 1587 . „Den XXen Mey.

DiRICK JANSz. Glaesmaker van Nijmagen JACOB CI,AESz. ${ }^{1}$ ) backer in $\mathrm{t}$ swartepaert".

$\mathrm{Na}$ het overlijden van DiRCK JANsz. werd, zooals wij gezien hebben, DiRCK REYNiersz. met de afwerking van het glas belast, waarmede hij eind Augustus 1604 is gereed gekomen. Daarna werd het in de kerk te Gouda geplaatst.

Hoewel Dirck Reyniersz. niet voorkomt in het Poorterboek van Delft, geeft zijne ondertrouw-acte in de zoogenaamden "Legger" de bijzonderheid, dat hij afkomstig was uit Eindhoven.

„Legger". 14 December I 585.

"DIRICr REYNIERSz. van Endoven Glaesscriver Jonckgeselle wonende in die Molenstraet.

Centgen Claesdr. Jonge doechter mede wonende aldair'.

In meer gemeld Haardstedengeld-register van I600, komt hij voor op folo. 40 :

„DIRCK REYNIERSZ. glaesemaker ende glaesescryver by syn aengeven haertsteden . . . . . . . . . . . . . . . . . . . . . . . II oven. . . . . . . . . . . . . . . . . . . . . . . . . . I".

DIRCK REYNIERSz. wordt ook in dit kohier uitdrukkelijk als ,glasschrijver vermeld en de aangifte van een vermoedelijk vrij grooten oven bevestigt zijn beroep.

DirCK Reyniersz. werd begraven 18 November 1608 in de Oude Kerk te Delift. De acte luidt: "DIRCK REYNIERSZ. glaesmaecker inde molestraet".

Zijne weduwe, CentGe ClaEsDR, overleefde hem negen jaten en werd mede in de Oude Kerk, ter aarde besteld en wel 28 October 1617. De eveneens hier beknopte acte luidt: "CENTGE CLAESDR, weduwe was van DIRCK REYNIERSZ. inde molestraet."

Deze Protestantsche familie woonde dus gedurende geruimen tijd in de Molenstraat, eene eenvoudige buurt in het Noorden van Delft, niet zoo deftig

1) De borg. 
als die van DIRCK JANSz, namelijk de Nieuwstraat, een zeer goede stand in het hartje van de stad. Later zal dan ook blijken, dat de kindskinderen van DIRCK REYNIERSz. het, zooals dat zoo schilderachtig heet in ons Nederlandsch, niet breed hadden, ofschoon hij zelf en zijn eigen kroost niet onbemiddeld waren.

Omtrent het huis van DiRCK Reyniersz, kan ik nog het volgende mede. deelen, ontleend aan de Boedelpapieren der Delftsche Weeskamer. 8 Mei 1590 koopt Dirck Reyniersz. een huis en erf, staande en gelegen in de Molenstraat, ven EliJSABETh HeIjNDRICKX, weduwe van Rochus CORNELISz., mandenmaker. In een Inventaris (Ao. I6I8) wordt deze woning als volgt beschreven: „Een huys ende erve staende inde molestraet met een huysken daerachter aenbelast int geheel opstal van twee ende twintich stuijvers acht penninghen sjaers".

Voorts bezat onze glasschilder nog twee huisjes aan den Verversdijk in de Huijch Andriesz.-poort of gang; een dier huisjes was "verheelt" aan zijne woning in de Molenstraat. I Maart $1618 \mathrm{w}$ erd het huis in de Molenstraat verkocht aan Pieter Pietersz, schilder, wonende op den Verversdijk, voor $f$ i 300 en even te voren was de tuin van DIRCK REYNiERsz. liggende aan de Oostzijde van den Verversdijk, naast het huis genaamd "t Radt van avontuijren" voor eene koopsom van $f$ i25, overgegaan in handen van ARENT SASBOUTSZ. VAN DER DUSsen.

Daar de doopboeken der Oude en Nieuwe Kerk te Delft eerst aanvangen Ao. I6I6 is het mij onmogelijk de doopacten der kinderen van DIRCK REyN IERSZ. te verstrekken. Intusschen vond ik vast één kind gemeld in het begraafregister der Oude Kerk, echter zonder aanteekening van naam, geslacht en leeftijd: I 3 Februari 1599. „Een kint van Dirck Revniersz. inde molestraet”.

Het Archief der Weeskamer te Delft, aenvangende circa 1618 (jammer genoeg is het oudste gedeelte geheel ${ }^{1}$ ) vernield door den brand van het Delftsche Stadhuis in genoemd jaar), geeft ons echter kostelijke inlichtingen.

In het Register van Comparitiën ter Weeskamer van Delft, deel II, folo. 4I5, lees ik het volgende:

${ }_{n}$ Dirck Reyniersz. Do u glaesmaecker.

Upten XXIII July anno XVIC negentyen hebben de voochden vande drie alsnoch onmondige kiuderen van zaligher Dirck Reyniersz. en C entgen Claesdr. by namen Cotnelis $\mathrm{S}$ ara en $\mathrm{C}$ entgen reeckeningh gedaen vande goederen byder voorsz. kinderen moeder als weduwe ende boelhouster metter doot nagelaten."

1) Eenige half verbrande papieren en stukken van dito registers zijn eitelijk nog over, doch ze zijn 200 zwaar beschadigd, dat ze vooralsnog buiten beschouwing kunnen blijven.

Mag ik hier even buiten mijn boekje gaan om eene kleine natuurwetenschappeiijke opmerking te maken? Indien men zijne neus diep steckt in deze balf verbrande papieren, wordt men eene zij't dan ook zwakke brandlucht gewaar, wel een bewijs dus der intensiteit van den geut van gebrand papier, welke na drie eeuwen nog merkbaar is. 
Uit een post in dato 8 December 1623 in het Reg.v. Comp. blijkt voorts, dat als administreerende voogd der genoemde drie kinderen optrad WiLleM Luytsz. KitTesteyn, schepen van Delft. Wij merkten reeds uit het hoofd der eerstgenoemde acte, dat er nu gesproken wordt van DiRCK REyniersz. Dou. Het patronymicum is derhalve opgelost. En straks zal blijken, dat de familienaam eigenlijk luidt VAN DER DOU, waarmede dus WILLEM TOMBERG, in den aanvang van dit opstel genoemd, geheel gerehabiliteerd wordt, doordat hij gesproken had van Dirck Reyniersz. van der Douw.

In het Register van Comparitiën komt vervolgens voor:

„Up huyden den XIIIIen February anno XVIC vierentwintich compareerde voor weesmeesteren Cornelis Dirxz. van der Dou zoon van zaligher Dirck Reyniersz. van der Dou slaesmaecker ende Centgen $\mathrm{Cla}$ esdr. alsnu gehuwelickt ende mondich zynde, ende bekende d'administratie zyner goederen zelfs aengenomen te hebben" enz. Op de gebruikelijke wijze bedankt hij dan zijne voogden voor de goede administratie zijner goederen en dechargeert hij Heeren Weemeesteren.

Cornelis Dircksz. VAN DER DOU trad te Delft 29 Juli 1623 in ondertrouw mef Neeltgen Clementsdr. de GrakfF.

"Legger" van Delft. 29 Juli I623.

"CORNFlis DirXz. VANDER DOU Jongghesel glaesmaecker wonende aen de voorstraet NeElTGen Clementsdr. DE GRAefF Jongedochter wonende aen beestemart."

Zij huwden, volgens het "Trouwboek" van Delft, I 3 Augustus I623, terwijl hun huwelijk werd ingezegend door den Delftschen predikant GIDEON VAN SONNEVELT.

Het register der Weeskamer vervolgende zien wij uit eene acte in dato I 2 Maart 1625, dat genoemde Willem Luytsz. KitTesteyn, de voogd der 2 nog onmondige kinderen, namens zijne medevoogden RIJCK CORNELISZ. VAN Es ${ }^{1}$ ) en LOURIS DIRCXZ. PRINSa) overlevert inventaris der goederen, nagelaten door Cornelis Dircksz. van der Dou.

De goederen van dien "glaesmaecker" waren echter, om de woorden der acte te gebruiken, "van cleender importantie".

Ten slotte vindt men nog eene acte in dato I3 Juli 1629 , waarbij de meerderjarig geworden CENTGE DIRCKS VAN DER DOU hare voogden bedankt voor de administratie harer goederen, welke zij nu zelt aanvaardt. In de acte voornoemd, de dato I2 Maart 1625 , komt als bijzonderheid nog voor, dat aan elk der kinderen SARA en CENTGE 34 guldens worden uitgekeerd, hierdoor haar "bevrijdende van alle lasten des boels."

Uit de Boedelpapieren der Weeskamer, reeds vermeld, (Archief der Weesls.

1) In de Boedelpapieren der Weeskamer: vAN DER EST.

a) In idem: LOURIS DIRCXz, in den PRINS.

Oud-Holland, $192 \pi$. 
No. 1415) blijkt nog, dat in 1619, behalve dan het te voren genoemde overleden kind en een eveneens gestorven zoon Claes, als kinderen van DirCK ReYNiersz. 1) in leven waren: Maritgen, weduwe van Hendrik Jacobsz., Cornelis, Sara, Centgen, benevens het kleinkind JANNETGEN ABRAHAMSDR., dochter van TRYNTJE, die gehuwd was geweest met Abraham Pittersz., "doosmaecker". In den "staet van de goederen" d.d. 23 Juli van genoemd jaar werden dezen 4 kinderen elk toegewezen 4 IO gulden II stuivers en 4 penningen, terwijl het kleinkind toekwamen 360 gulden I I stuivers en 7 penningen.

Wij behoeven te dezer plaatse de genealogie van het geslacht VAN DER Dou niet nader te preciseeren of uit te werken. Wel is van belang de namen der "glaesmaeckers" te vermelden, welke ik nog in de Poedelpapieren gevonden heb en onder wie ook "glasscrijvers" kunnen schuilen.

Ze zijn :

r. "Willem Bartelmeesz,, glaesmaecker op Beijerlant."

2. "ARIJEN LuCASZ. glasemaker in den Briel."

3. "MEIJNERT Fransz,, glaesmaecker in St. Ursulenstraet”, te Delft.

4. "Frans Maertensz., glaesmaecker" te Delft.

5. "HeYNDRICK GILLISZ., glaesmaecker in den hage."

6. "MONTFOORT, glaesmaecker in den Hage."

7. "JAN JORISZ., glaesmaecker tot Schiedam."

8. "CORNELIS JANSZ., glaesmaecker tot Spijckenis."

Omtrent de techniek van het glasbranden en desbetreffende gereedschappen vond ik tot mijne spijt geene nadere bijzonderheden in het Archief der Weeskamer. Alleen teeken ik nog aan uit den Inventaris (16I8), liggende onder de Boedelpapieren:

$$
\text { "INT VOORHUIJS". }
$$

"Inden eersten een tafel met eenich gereedschap, dienende tot het ambacht van glaessen maccken", en ofschoon hier niet ter zake dienende, is het toch vermeldenswaard, dat in het voorhuis nog aanwezig waren: "Twee contrafeijtsels d'eene van DirCK Reyniersz. zaligher, ende Centgen Claesdr."

Het is mogelijk, dat het Rechterlijk Archief van Delft, doch vooral de Notarieele Protocollen nog meer gegevens omtrent de twee Delftsche glasschilders kunnen verschaffen. Beide verzamelingen berusten, zooals bekend is, ten Algemeenen Rijksarhieve te 's-Gravenhahe, en zijn door mij in dit opzicht nog niet geraadpleegd. Op het hier alreede onderzochte en medegedeelde kan thans met zekerheid worden voortgebouwd.

1) Nog wordt $A^{\circ}$. 1618 genoemd een broeder van DirCik Reynirssz, name.jjk Jan Reyriersz. "harnesschoonmaecker." 